BMJ Open

Diabetes

Research

\& Care

\title{
Effect of medication adherence on clinical outcomes in type 2 diabetes: analysis of the SIMPLE study
}

\author{
Sapna Patel (D) , ${ }^{1}$ Marconi Abreu, ${ }^{1}$ Anna Tumyan, ${ }^{1}$ Beverley Adams-Huet, ${ }^{2}$ \\ Xilong Li, ${ }^{2}$ Ildiko Lingvay ${ }^{1}$
}

To cite: Patel S, Abreu M, Tumyan A, et al. Effect of medication adherence on clinical outcomes in type 2 diabetes: analysis of the SIMPLE study. BMJ Open Diab Res Care 2019;7:e000761. doi:10.1136/ bmjdrc-2019-000761

Received 15 July 2019 Revised 28 September 2019 Accepted 23 October 2019

Check for updates

(C) Author(s) (or their employer(s)) 2019. Re-use permitted under CC BY-NC. No commercial re-use. See rights and permissions. Published by BMJ.

${ }^{1}$ Endocrinology, Diabetes and Metabolism, University of Texas Southwestern Medical Center at Dallas, Dallas, Texas, USA ${ }^{2}$ Population and Data Sciences, University of Texas Southwestern Medical Center at Dallas, Dallas, Texas, USA

Correspondence to Dr Ildiko Lingvay; Ildiko.Lingvay@ UTSouthwestern.edu

\section{ABSTRACT}

Objective Medication adherence is impacted by regimen complexity. The SIMPLE (Simple basal Insulin titration, Metformin Plus Liraglutide for type 2 diabetes with very Elevated HbA1c) study compared GLP1RA plus basal insulin (GLP1RA+BI) to basal-bolus insulin (BBI) regimen in participants with very uncontrolled type 2 diabetes mellitus (T2DM). This analysis aimed to evaluate medication adherence to GLP1RA+BI compared with BBI, the effect of adherence on clinical and patient-reported outcomes, and baseline predictors of adherence.

Research design and methods This was an analysis of the SIMPLE study based on prespecified outcome. The study took place in pragmatic, real-world setting. A total of 120 adults with T2DM and $\mathrm{HgbA} 1 \mathrm{c} \geq 10 \%$ were randomized to detemir plus liraglutide, or detemir plus aspart before each meal; 6-month follow-up. The main outcomes evaluated were: adherence, HgbA1c, weight, quality of life, and hypoglycemia. Adherence rate was calculated for each study medication at each follow-up visit; participants were classified as $\geq 80 \%$ or $<80 \%$ adherent.

Result A higher percentage of participants in the GLP1RA+Bl compared with the BBI group had $\geq 80 \%$ adherence to detemir ( $59.3 \%$ vs $35.7 \%, p=0.02$ ) as well as liraglutide versus aspart ( $57.4 \%$ vs $30.4 \%, p=0.007$ ). Higher age was predictive of $\geq 80 \%$ adherence (OR per 5-year increment=1.48, 95\% Cl 1.09 to 2.0, $p=0.01$ ). Higher adherence led to greater improvement in $\mathrm{HbA} 1 \mathrm{c}$ and weight in both groups. Treatment with GLP1RA+BI compared with $\mathrm{BBI}$ led to greater improvement in $\mathrm{HbA1C}$, weight, and quality of life and lower risk of hypoglycemia even after adjusting for the difference in adherence between groups.

Conclusions Adherence was higher with the simplified regimen of GLP1RA+BI compared with $\mathrm{BBI}$. Greater adherence to the simpler regimen amplified the treatment effect on $\mathrm{HbA1C}$, weight, quality of life, and risk of hypoglycemia, yet statistically significant greater benefits were noted even when adjusted for adherence.

Trial registration number NCT01966978

\section{INTRODUCTION}

Diabetes prevalence in the US adult population was estimated at 14\% from 2013 to 2016, which includes $9.3 \%$ diagnosed diabetes and $4.3 \%$ undiagnosed diabetes. ${ }^{1}$ According to the Centers for Disease Control and Prevention 2011 data, $30.8 \%$ of patients diagnosed

\section{Significance of this study}

What is already known about this subject?

- The rate of adherence with glucose-lowering medications is associated with glycemic control.

- Adherence to glucose-lowering agents in adults with type 2 diabetes is low.

- The complexity of the treatment regimen is an important contributor to medication adherence rate.

What are the new findings?

- Medication adherence is greater with glucagon-like peptide-1 receptor agonist (GLP1RA) plus basal insulin compared with basal-bolus insulin.

- The GLP1RA plus basal insulin treatment group had improved glycemic control, greater weight loss and lower risk of hypoglycemia compared with the basal-bolus insulin group.

\section{How might these results change the focus of}

research or clinical practice?

- A less complex treatment regimen improves medication adherence.

- Treatment with GLP1RA plus basal insulin compared with basal-bolus insulin regimen led to greater improvement in glucose control, as well as better weight profile, less likelihood of hypoglycemia, and improved quality of life.

with diabetes are treated with either insulin alone or insulin plus oral agents. ${ }^{2}$ Approximately $50 \%$ of patients with type 2 diabetes mellitus (T2DM) are not at target glycemic control of HbA1c $<7 \%,{ }^{3}$ an outcome that is at least partially due to poor adherence to medication. ${ }^{4}$ Poor adherence to glucoselowering agents can result in poor glycemic control and may lead to increased hospitalization, diabetic complications, and healthcare resource use. ${ }^{5}$

Adherence to chronic therapies is disappointing in many chronic disease states. ${ }^{6}$ Adherence to glucose-lowering agents has been shown to be low overall. For example, Farr et al reported that in the USA, adherence rates measured as proportion of days covered 
(PDC) $\geq 80 \%$ were less than $50 \%$ across three oral glucoselowering classes at 1 year after initiation, and even lower at the 2 years after initiation where adherence was approximately $40 \%{ }^{7}$ Non-adherence to glucose-lowering agents is influenced by multiple factors including tolerability, efficacy, cost of medications, complexity of the treatment regimen (frequency and route of administration, number of additional agents in the treatment regimen), and patient-provider interaction. ${ }^{89}$ Adherence to injectable therapies like insulin is very low, especially if multiple daily injections are prescribed. ${ }^{10}$ Pfeiffer et al evaluated 398 patients treated with basal-bolus insulin (BBI) regimen and concluded that the complicated nature of basal-bolus therapy contributes to the difficulties that patients with type 2 diabetes (T2D) have with the regimen and low adherence rates. ${ }^{10}$ Even with the newer classes of injectable glucose-lowering agents, the glucagon-like peptide-1 receptor agonists (GLP1RA), adherence has been low, with retrospective studies showing PDC $\geq 80 \%$ of $34 \%-54.2 \% .{ }^{11}{ }^{12}$ GLP1RAs are potent glucose-lowering agents, and when used in conjunction with insulin they can further improve glycemic control, lower the dose of insulin, and minimize hypoglycemia. ${ }^{13}$ Combination therapy with a GLP1RA plus basal insulin (GLP1RA+BI) is effective and more convenient compared with either a BBI or even less intense insulin-based regimens like basalplus one or premixed insulins. ${ }^{14-18}$ The GLP1RA+BI can be administered at the same time of the day, irrespective of meals, can be easily self-titrated by the patients, and therefore a more desirable treatment strategy compared with other more complex insulin-based regimens, which could also translate to increased adherence to therapy. ${ }^{19}$

The SIMPLE (Simple basal Insulin titration, Metformin Plus Liraglutide for type 2 diabetes with very Elevated HbA1c) study was a randomized trial which compared two treatment strategies (GLP1RA+BI vs BBI) in participants with T2DM and very elevated HbA1c $(\geq 10 \%)$. A total of 120 participants were randomized with an average age of $47.4 \pm 9.5$, diabetes duration of $10.5 \pm 7.2$ years, and $\mathrm{HbA1c}$ $12.1 \% \pm 1.4 \%$. Treatment with GLP1RA+BI improved HgbA1c more than treatment with BBI regimen (estimated treatment difference (ETD) of $-1.1 \%, 95 \%$ CI $-2.0 \%$ to $-0.1 \%, \mathrm{p}=0.03$ ), while this group also had better weight outcomes (ETD $-3.7 \mathrm{~kg}, 95 \%$ CI -5.8 to -1.5 , $\mathrm{p}=0.001)$, lower risk of hypoglycemia $(35.2 \%$ vs $66.1 \%$, respectively) and greater improvement in several quality of life (QoL) domains. ${ }^{18}$

The objective of this analysis is to compare adherence between the two treatment strategies, assess if any baseline characteristics predict adherence to treatment, and evaluate the impact of adherence on relevant clinical outcomes (HbAlc, weight, and hypoglycemia) and patient-reported outcomes (QoL).

\section{MATERIALS AND METHODS}

This is an analysis of the SIMPLE study, which was a prospective, randomized, open-label, parallel group trial comparing two treatment strategies (GLP1RA+BI vs $\mathrm{BBI}$ ), both in addition to metformin in individuals with very uncontrolled $(\mathrm{HbA} 1 \mathrm{c} \geq 10 \%)$ T2D. The intention-totreat data set of the SIMPLE trial included $n=110$ with 54 patients in GLP1RA+BI group and 56 patients in the BBI group. $^{18}$

\section{Eligibility}

In the SIMPLE study, participants were recruited from the outpatient clinics at Parkland Health and Hospital System if they were $\geq 18$ years of age and had T2DM with a confirmed HgbA1c $\geq 10 \%$. Participants were excluded if they had type 1 diabetes, were using prandial insulin (or had used it within the past 30 days), DDP-4 inhibitors or GLP1RA, had a history of pancreatitis or pancreatic disease, a baseline lipase level more than three times the upper limit of normal, creatinine clearance $<30 \mathrm{~mL} / \mathrm{min}$, or decompensated comorbidities.

\section{Intervention and medication titration}

All participants initiated basal insulin detemir at randomization and self-titrated the dose daily according to a prespecified protocol targeting a fasting blood glucose of $71-100 \mathrm{mg} / \mathrm{dL}$.

Participants randomized to the GLP1RA+BI treatment group were initiated on liraglutide and titrated according to the label to the final dose of $1.8 \mathrm{mg} /$ day, or highest tolerated dose. Participants randomized to the BBI initiated insulin aspart subcutaneously before each main meal and self-titrated the dose according to a prespecified protocol.

Metformin was continued or initiated and titrated after randomization if not contraindicated. The dose was titrated to maximum tolerated dose or to $1000 \mathrm{mg}$ twice daily. A full description of the study design, interventions, and outcomes can be found in the primary manuscript. ${ }^{18}$

Liraglutide, insulin detemir and insulin aspart were all dispensed in prefilled pen devices and provided at no cost to participants throughout the study. Participants were required to return all study medications (used or unused) at each clinic visit. Follow-up clinic visits occurred at 1, 3, and 6 months after randomization. An adherence rate was calculated for each study medication at each visit by dividing the amount of each product used by the expected amount of product to be used over the number of days between the respective visits. Adherence to metformin, which was not provided by the study, was based on pharmacy product fill rate. All participants recorded their daily insulin dose in a study-specific logbook which was reviewed at each visit and used to calculate the expected amount of product to be used.

\section{Assessments}

For analysis purpose, participants were considered 'adherent' if they had at least two (out of three) visits where adherence could be assessed (product was returned) and the calculated time-adjusted average adherence rate for the entire duration of the study was 


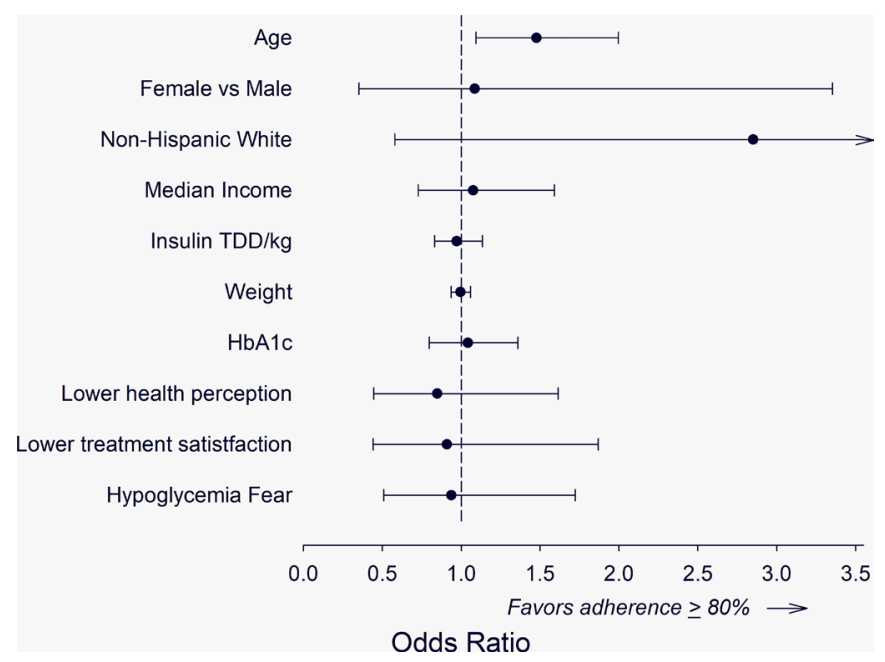

Figure 1 Baseline characteristics as predictors of $\geq 80 \%$ adherence. The units for the baseline variables associated with the ORs for adherence $\geq 80 \%$ are age per 5 years, median income per $\$ 10000$, insulin TDD/kg per 0.1 unit, weight per $5 \mathrm{~kg}$ and $\mathrm{HbA} 1 \mathrm{c}$ per $1 \%$. TDD, total daily dose.

$\geq 80 \%$. Participants who did not meet these criteria were considered $<80 \%$ adherent.

Age, gender, and race were self-reported by participants. Weight was measured on the same scale at each visit in accordance with usual clinic procedures (no shoes or outerwear, empty pockets). HgbA1c was measured in the local laboratory at baseline, 3 and 6 months' follow-up. QoL was assessed via a modified Diabetes Quality of Life Clinical Trial Questionnaire at the time of randomization and at the 6-month clinic visit, and reported as individual domain scores.

Hypoglycemia was defined as a blood glucose level of $<70 \mathrm{mg} / \mathrm{dL}$ regardless of symptoms, or if a participant needed assistance from a third party to treat symptoms suggestive of hypoglycemia regardless of whether a blood glucose measurement was performed.

\section{Statistical analysis}

We summarized the percent of participants with $\geq 80 \%$ and $<80 \%$ adherence in each treatment group and by each glucose-lowering medication separately (metformin, insulin detemir, insulin aspart, liraglutide). Detemir insulin was provided by the study to participants in both randomized groups, therefore we used adherence to detemir (the common denominator for both treatment groups) for all further analyses. Predictors of detemir adherence were evaluated with univariable and multivariable logistic regression models. Covariates assessed were age, race, gender, baseline $\mathrm{HbA1c}$, insulin total daily dose (TDD) $/ \mathrm{kg}$, weight, QoL, and median income. Treatment group comparisons controlling for adherence and change from baseline contrasts by adherence stratum were made with mixed effects models for the outcomes of HbAlc, weight, and QoL. Binomial frequencies were compared between groups with the Fisher's exact test. Hypoglycemia was analyzed with Cochran
Mantel-Haenszel tests, stratifying by adherence status. A two-sided alpha $=0.05$ was used for hypothesis testing. Analysis was conducted with SAS V.9.4 (SAS Institute).

\section{RESULTS}

We randomized 120 participants with an average age of 47 years, $71 \%$ female, and a high minority representation (40\% Hispanic, $42 \%$ African-American), with a 10 -year average duration since diagnosis of diabetes and mean baseline HbAlc of $12.1 \%$. The majority of patients $(76 \%)$ were already treated with insulin prior to enrollment.

\section{Adherence between groups}

The percentage of participants with $\geq 80 \%$ adherence to detemir insulin was higher in the GLP1RA+BI group $(\mathrm{n}=32,59.3 \%)$ versus the BBI group $(\mathrm{n}=20,35.7 \%)$ ( $\mathrm{p}=0.021$ between groups). The percentage of participants with $\geq 80 \%$ adherence to liraglutide was $57.4 \%$ compared with aspart insulin $30.4 \% \quad(p=0.007$ between groups). The percentage of participants with $\geq 80 \%$ adherence with metformin was similar between groups (66.7\% in the GLP1RA+BI group and $60.7 \%$ in the BBI group, $\mathrm{p}=0.556$ between groups).

\section{Baseline characteristics as predictors of adherence}

Age was the only significant predictor of future adherence with detemir insulin, when adjusted for treatment group. ORs for univariable predictors of detemir adherence for all participants combined are shown in figure 1. Higher age was predictive of $\geq 80 \%$ adherence to detemir (OR per 5-year increment $=1.48,95 \%$ CI 1.09 to $2.00, \mathrm{p}=0.01$ ). Gender, race, income, baseline HbA1c, weight, insulin TDD, and diabetes-related QoL were not associated with adherence in univariable nor multivariable models.

\section{Effect of adherence on clinical and patient-reported outcomes $\mathrm{HbA1c}$ and weight}

To explore whether the difference in adherence between the two treatment arms was responsible for the reported clinical benefits, we compared the change in HbAlc and weight between groups adjusting for the adherence rates. The reduction in HbA1c was greater in the GLP1RA+BI group compared with the BBI group after adjustment for adherence (ETD $-0.91,95 \%$ CI -1.86 to 0.03 , $\mathrm{p}=0.058$ ). In both treatment groups, participants with $\geq 80 \%$ adherence had numerically greater reduction in HgbAlc than participants with $<80 \%$ adherence, and a numerically greater reduction in HgbA1c was noted in the GLP1RA versus BBI group in both $\geq 80 \%$ adherence and $<80 \%$ adherence groups (table 1 ).

A significant difference between groups in terms of weight change was observed after controlling for the adherence rates (ETD $-3.8 \mathrm{~kg}, 95 \%$ CI -6.0 to -1.6 , $\mathrm{p}<0.001)$. Participants with $\geq 80 \%$ adherence treated with GLP1RA+BI observed weight loss $(-1.2 \mathrm{~kg}$; $95 \% \mathrm{CI}$ -3.1 to 0.6$)$, while those treated with BBI had weight gain $(+4.5 \mathrm{~kg} ; 95 \%$ CI 2.2 to 6.9$)$. Participants with $<80 \%$ 
Table 1 Clinical and patient-reported outcomes with change from baseline to 6 months for patients with $\geq 80 \%$ adherence and $<80 \%$ adherence

\begin{tabular}{|c|c|c|c|c|}
\hline \multirow[b]{3}{*}{ Outcome } & \multicolumn{2}{|c|}{ GLP1RA+basal insulin group } & \multicolumn{2}{|c|}{ Basal-bolus insulin group } \\
\hline & \multicolumn{2}{|l|}{ Month 6 to baseline } & \multicolumn{2}{|l|}{ Month 6 to baseline } \\
\hline & $\geq 80 \%$ adherence $\mathrm{n}=32$ & $<80 \%$ adherence $\mathrm{n}=22$ & $\geq \mathbf{8 0} \%$ adherence $n=20$ & $<80 \%$ adherence $n=36$ \\
\hline Weight (kg) & $-1.3(-3.2$ to 0.67$)$ & $0.31(-2.2$ to 2.9$)$ & $4.6(2.2$ to 7.0$)$ & $2.1(0.1$ to 4.0$)$ \\
\hline \multicolumn{5}{|l|}{ D-QOL } \\
\hline Treatment satisfaction & $-0.59(-0.86$ to -0.32$)$ & $-0.65(-0.98$ to -0.31$)$ & $-0.25(-0.59$ to 0.08$)$ & $-0.25(-0.55$ to 0.04$)$ \\
\hline Hypoglycemia fear & $-0.18(-0.46$ to 0.10$)$ & $-0.28(-0.62$ to 0.06$)$ & $0.04(-0.32$ to 0.39$)$ & $0.44(0.14$ to 0.75$)$ \\
\hline
\end{tabular}

Results are least squares mean change from baseline (95\% Cls) from mixed effects linear models.

D-QOL, Diabetes Quality of Life Questionnaire; GLP1RA, glucagon-like peptide-1 receptor agonist.

adherence had no significant change in weight regardless of treatment group (table 1).

\section{Quality of life}

A lower QoL score indicates better QoL, that is, a decreased score corresponds with improved QoL. General health perception was improved in participants treated with GLP1RA+BI versus BBI even after adjustment for adherence (ETD $-0.53,95 \%$ CI -0.92 to -0.15 , $\mathrm{p}=0.007)$. Treatment satisfaction and fear of hypoglycemia improved more in the GLP1RA+BI group compared with BBI group even when adjusting for adherence (ETD $-0.36,95 \%$ CI -0.67 to $-0.06, p=0.02$; ETD $-0.47,95 \%$ CI -0.79 to $-0.15, \mathrm{p}=0.005$, respectively), while changes in current health perception and diabetes-related worry were similar after adjustment for adherence.

Regardless of adherence rate, the group treated with GLP1RA+BI had a significant improvement in both general health perception as well as treatment satisfaction (table 1). Fear of hypoglycemia numerically improved, regardless of adherence, in the GLP1RA+BI group and numerically increased in the BBI groups (table 1).

\section{Hypoglycemia}

Participants in the BBI treatment group were twice as likely to have at least one hypoglycemic event compared with the GLP1RA+BI in both the $\geq 80 \%$ adherent $(80.0 \%$ vs $40.6 \% ; \mathrm{p}=0.009)$ and $<80 \%$ adherent subgroups (58.3\% vs $27.3 \%$; $\mathrm{p}=0.03)$.

\section{DISCUSSION}

We evaluated a patient population with uncontrolled T2D with $\mathrm{HgbA} 1 \mathrm{c} \geq 10.0 \%$ and compared adherence between the standard treatment group (BBI) and a less complex treatment regimen (GLP1RA+BI). We found that participants randomized to the simpler regimen consisting of GLP1RA+BI were more likely to have $\geq 80 \%$ adherence with detemir insulin and liraglutide compared with those randomized to BBI and treated with detemir insulin and aspart. Higher age was the only predictor of $\geq 80 \%$ adherence within each treatment group. Treatment with
GLP1RA+BI, compared with BBI, led to improvement in HbAlc and weight, lower risk of hypoglycemia, and improved general health perception, treatment satisfaction, and fear of hypoglycemia even after adjustment for difference in adherence between treatment groups. Those with $\geq 80 \%$ adherence, compared with those who had lower adherence, had numerically greater effects on HbAlc and weight, but were more likely to experience hypoglycemia.

Adherence with both oral and injectable glucoselowering agents is very low and this significantly contributes to inadequate glycemic control in patients with T2DM. ${ }^{20-24}$ Complexity of a treatment regimen is one of the main reasons for limited adherence to medications. ${ }^{1025}$ Prior studies have shown that a less complex regimen with GLP1RA+BI compared with BBI provides similar glycemic control, with greater weight loss and lower hypoglycemic risk, ${ }^{26-28}$ but none of these studies enrolled patients with elevated HbAlc. This population was exclusively targeted in our study, thus adding to the body of evidence supporting the efficacy and safety of this simpler regimen in this particular population which traditionally has proven to be the more challenging to treat and disproportionately affected by poor adherence. Higher adherence $(\geq 80 \%)$ to either insulin or GLP1RA is associated with better clinical outcomes, ${ }^{411} 23$ however adherence with GLP1RA+BI versus BBI has not been previously studied. This is the first report evaluating adherence to GLP1RA+BI and BBI in a population of patients with very elevated HgbAlc $(\geq 10 \%)$ and the associated clinical outcomes. These data emphasize and support the findings in the literature promoting less complex treatment regimens for greater adherence with the goal of achieving greater improvements in glycemic control, weight management and reduced risk of hypoglycemic events. In fact, adherence to all components of the treatment regimen was affected by the complexity of the regime as we found that adherence to detemir was similar to that of liraglutide in the GLP1RA+BI group, while adherence to detemir was lower and similar to aspart in the BBI group. 
This study was conducted in a county health system, and had a pragmatic design fully embedded in the usual clinical setting. This included the frequency of follow-ups which were in accordance with our clinical practice (and less frequent compared with a usual clinical trial), requirement for self-titration of all medications, and unscheduled contacts limited to those initiated by the participants. As such, these findings are readily translatable to real-world usual clinical practice. Additionally, we directly assessed adherence with each individual agent at each encounter, therefore the estimate of adherence in our study is more precise than reports using pharmacy fill rates as a measure of adherence.

Several limitations are noteworthy. First, calculation of adherence was predicated on participants returning their study medication. If adherence could not be calculated, the participant was included in the $<80 \%$ adherence group. While this is a conservative approach, it could have underestimated the true adherence rate. Second, after dividing each treatment group by adherence, the number of participants in each subgroup was small and inadequately powered for meaningful comparisons between these subgroups. As such, only numerical comparisons were performed across these subgroups (table 1). Third, adherence was a secondary outcome and even though it was a prespecified outcome results should be hypothesis generating and interpreted in the context of other findings from similar trials. Lastly, insulin detemir, aspart, and liraglutide were provided free of charge to participants. Adherence in such setting could be overestimated compared with the real-world setting where cost of acquiring a medication plays a significant role in adherence.

In conclusion, our results suggest that a less complex treatment regimen consisting of GLP1RA+BI, compared with $\mathrm{BBI}$ therapy, is associated with greater adherence as well as improved clinical outcomes (HbAlc, weight, hypoglycemia) and improved QoL (general health perception, treatment satisfaction and hypoglycemia fear). GLP1RA+BI is a safe and effective treatment option for patients with very uncontrolled T2DM.

Contributors SP, MA, BAH and IL contributed to the conception and design of the study, the acquisition, analysis and interpretation of data. AT and XL contributed to the analysis and interpretation of data. SP, MA, BAH, IL, and AT drafted the work and revised it critically for important intellectual content. All authors approved the final version to be published; agree to be accountable for all aspects of the work in ensuring that questions related to the accuracy or integrity of any part of the work are appropriately investigated and resolved.

Funding This work was supported by an Investigator-Initiated Study Grant from Novo Nordisk to IL.

Competing interests IL received honoraria for consulting/advising boards from Novo Nordisk, Eli Lilly, Sanofi, Intarcia Therapeutics, AstraZeneca, Valeritas, MannKind, TARGET Pharma, Boehringer Ingelheim and research grants from Novo Nordisk, Merck, Gl Dynamics, Pfizer, Novartis, and Mylan. BAH has consulted for Valeritas outside the submitted work. MA has consulted for Novo Nordisk outside the submitted work.

Patient consent for publication Not required.

Provenance and peer review Not commissioned; externally peer reviewed.
Data availability statement Data are available upon reasonable request. All data relevant to the study are included in the article or uploaded as supplementary information.

Open access This is an open access article distributed in accordance with the Creative Commons Attribution Non Commercial (CC BY-NC 4.0) license, which permits others to distribute, remix, adapt, build upon this work non-commercially, and license their derivative works on different terms, provided the original work is properly cited, appropriate credit is given, any changes made indicated, and the use is non-commercial. See: http://creativecommons.org/licenses/by-nc/4.0/.

ORCID iD

Sapna Patel http://orcid.org/0000-0002-8069-9012

\section{REFERENCES}

1 Mendola ND, Chen TC, Gu Q, et al. NCHS data brief, 2018. Available: https://www.cdc.gov/nchs/products/databriefs/db319.htm [Accessed 17 Jun 2019].

2 Centers for Disease Control and Prevention. Age-Adjusted percentage of adults with diabetes using diabetes medication, by type of medication, United States, 1997-2011, 2012. Available: https://www.cdc.gov/diabetes/statistics/meduse/fig2.htm [Accessed 10 Jun 2019].

3 Cowie CC. Diabetes diagnosis and control: missed opportunities to improve health. Diabetes Care 2019;42:994-1004.

4 Kindmalm L, Melander A, Nilsson JLG. Refill adherence of antihyperglycaemic drugs related to glucose control $(\mathrm{HbA1c})$ in patients with type 2 diabetes. Acta Diabetol 2007;44:209-13.

5 Fukuda $\mathrm{H}$, Mizobe M. Impact of nonadherence on complication risks and healthcare costs in patients newly-diagnosed with diabetes. Diabetes Res Clin Pract 2017;123:55-62.

6 Yeaw J, Benner JS, Walt JG, et al. Comparing adherence and persistence across 6 chronic medication classes. J Manag Care Pharm 2009;15:728-40.

7 Farr AM, Sheehan JJ, Curkendall SM, et al. Retrospective analysis of long-term adherence to and persistence with DPP-4 inhibitors in US adults with type 2 diabetes mellitus. Adv Ther 2014;31:1287-305.

8 Blackburn DF, Swidrovich J, Lemstra M. Non-adherence in type 2 diabetes: practical considerations for interpreting the literature. Patient Prefer Adherence 2013;7:183-9.

9 Spain CV, Wright JJ, Hahn RM, et al. Self-Reported barriers to adherence and persistence to treatment with injectable medications for type 2 diabetes. Clin Ther 2016;38:1653-64.

10 Pfeiffer KM, Basse A, Lee XY, et al. Diabetes management and healthcare resource use when Intensifying from basal insulin to Basal-Bolus: a survey of type 2 diabetes patients. Diabetes Ther 2018;9:1931-44.

11 Buysman EK, Liu F, Hammer M, et al. Impact of medication adherence and persistence on clinical and economic outcomes in patients with type 2 diabetes treated with liraglutide: a retrospective cohort study. Adv Ther 2015;32:341-55.

12 Alatorre C, Fernández Landó L, Yu M, et al. Treatment patterns in patients with type 2 diabetes mellitus treated with glucagon-like peptide-1 receptor agonists: higher adherence and persistence with dulaglutide compared with once-weekly exenatide and liraglutide. Diabetes Obes Metab 2017;19:953-61.

13 Wysham CH, Lin J, Kuritzky L. Safety and efficacy of a glucagonlike peptide-1 receptor agonist added to basal insulin therapy versus basal insulin with or without a rapid-acting insulin in patients with type 2 diabetes: results of a meta-analysis. Postgrad Med 2017; 129:436-45.

14 Dalal MR, Xie L, Baser O, et al. Adding rapid-acting insulin or GLP-1 receptor agonist to basal insulin: outcomes in a community setting. Endocr Pract 2015;21:68-76.

15 Abd El Aziz MS, Kahle M, Meier JJ, et al. A meta-analysis comparing clinical effects of short- or long-acting GLP-1 receptor agonists versus insulin treatment from head-to-head studies in type 2 diabetic patients. Diabetes Obes Metab 2017;19:216-27.

16 Levin P, Fan T, Song X, et al. Comparing clinical outcomes and costs for different treatment intensification approaches in patients with type 2 diabetes uncontrolled on basal insulin: adding glucagon-like peptide 1 receptor agonists versus adding rapid-acting insulin or increasing basal insulin dose. Endocr Pract 2017;23:1316-24.

17 Kallenbach L, Shui AM, Cheng WY, et al. Predictors and clinical outcomes of treatment intensification in patients with type 2 diabetes uncontrolled on basal insulin in a real-world setting. Endocr Pract 2018;24:805-14.

18 Abreu M, Tumyan A, Elhassan A, et al. A randomized trial comparing the efficacy and safety of treating patients with type 2 diabetes and 
highly elevated $\mathrm{HbA} 1 \mathrm{c}$ levels with basal-bolus insulin or a glucagonlike peptide-1 receptor agonist plus basal-bolus insulin: the simple study. Diabetes Obes Metab 2019;21:2133-41.

19 Yamamoto S, Hayashi T, Ohara M, et al. Comparison of liraglutide plus basal insulin and basal-bolus insulin therapy (BBIT) for glycemic control, body weight stability, and treatment satisfaction in patients treated using BBIT for type 2 diabetes without severe insulin deficiency: a randomized prospective pilot study. Diabetes Res Clin Pract 2018;140:339-46.

20 Edelman SV, Polonsky WH. Type 2 diabetes in the real world: the elusive nature of glycemic control. Diabetes Care 2017;40:1425-32.

21 Hertz RP, Unger AN, Lustik MB. Adherence with pharmacotherapy for type 2 diabetes: a retrospective cohort study of adults with employer-sponsored health insurance. Clin Ther 2005;27:1064-73.

22 Cai J, Wang Y, Baser O, et al. Comparative persistence and adherence with newer anti-hyperglycemic agents to treat patients with type 2 diabetes in the United States. $J$ Med Econ 2016;19:1175-86.

23 Carls GS, Tuttle E, Tan R-D, et al. Understanding the gap between efficacy in randomized controlled trials and effectiveness in real- world use of GLP-1 RA and DPP-4 therapies in patients with type 2 diabetes. Diabetes Care 2017;40:1469-78.

24 Donnelly LA, Morris AD, Evans JMM, et al. Adherence to insulin and its association with glycaemic control in patients with type 2 diabetes. QJM 2007;100:345-50.

25 García-Pérez L-E, Alvarez M, Dilla T, et al. Adherence to therapies in patients with type 2 diabetes. Diabetes Ther 2013;4:175-94.

26 Castellana M, Cignarelli A, Brescia F, et al. Glp-1 receptor agonist added to insulin versus basal-plus or basal-bolus insulin therapy in type 2 diabetes: a systematic review and meta-analysis. Diabetes Metab Res Rev 2019;35:e3082.

27 Rosenstock J, Guerci B, Hanefeld M, et al. Prandial options to advance basal insulin Glargine therapy: testing Lixisenatide plus basal insulin versus insulin Glulisine either as Basal-Plus or BasalBolus in type 2 diabetes: the GetGoal Duo-2 trial. Diabetes Care 2016;39:1318-28.

28 Billings LK, Doshi A, Gouet D, et al. Efficacy and safety of IDegLira versus basal-bolus insulin therapy in patients with type 2 diabetes uncontrolled on metformin and basal insulin; dual VII randomized clinical trial. diabetes care 2018;41:1009-16. 